\title{
Cd1d-dependent regulation of bacterial colonization in the intestine of mice
}

\author{
Edward E.S. Nieuwenhuis,, 1,2 Tetsuya Matsumoto, 1,3 Dicky Lindenbergh, ${ }^{2}$ Rob Willemsen,4 \\ Arthur Kaser, ${ }^{1}$ Ytje Simons-Oosterhuis, ${ }^{2}$ Sylvia Brugman, ${ }^{2}$ Keizo Yamaguchi, ${ }^{5}$ Hiroki Ishikawa, ${ }^{6}$ \\ Yuji Aiba, ${ }^{6}$ Yasuhiro Koga, ${ }^{6}$ Janneke N. Samsom, ${ }^{2}$ Kenshiro Oshima,7 Mami Kikuchi,7,8 \\ Johanna C. Escher, ${ }^{2}$ Masahira Hattori,7 Andrew B. Onderdonk, ${ }^{9}$ and Richard S. Blumberg ${ }^{1}$ \\ ${ }^{1}$ Gastroenterology Division, Department of Medicine, Brigham and Women's Hospital, Harvard Medical School, Boston, Massachusetts, USA. \\ 2Laboratory of Pediatrics, Erasmus Medical Center, Rotterdam, The Netherlands. ${ }^{3}$ Department of Microbiology, Tokyo Medical University, Tokyo, Japan. \\ ${ }^{4}$ Department of Clinical Genetics, Erasmus Medical Center, Rotterdam, The Netherlands. ${ }^{5}$ Department of Microbiology, Toho University School of Medicine, \\ Tokyo, Japan. ${ }^{6}$ Department of Infectious Diseases, Tokai University School of Medicine, Kanagawa, Japan. 7 Graduate School of Frontier Sciences, \\ University of Tokyo, Kashiwanoha, Kashiwa, Japan. ${ }^{8}$ Biomedical Research Laboratories, Kureha Corporation, Hyakunin-cho, Shinjuku, Tokyo, Japan. \\ ${ }^{9}$ Channing Laboratory, Department of Pathology, Harvard Medical School, Boston, Massachusetts, USA.
}

\begin{abstract}
The accumulation of certain species of bacteria in the intestine is involved in both tissue homeostasis and immune-mediated pathologies. The host mechanisms involved in controlling intestinal colonization with commensal bacteria are poorly understood. We observed that under specific pathogen-free or germ-free conditions, intragastric administration of Pseudomonas aeruginosa, E. coli, Staphylococcus aureus, or Lactobacillus gasseri resulted in increased colonization of the small intestine and bacterial translocation in mice lacking Cd1d, an MHC class I-like molecule, compared with WT mice. In contrast, activation of Cd1d-restricted T cells (NKT cells) with $\alpha$-galactosylceramide caused diminished intestinal colonization with the same bacterial strains. We also found prominent differences in the composition of intestinal microbiota, including increased adherent bacteria, in $C d 1 d^{-/-}$mice in comparison to WT mice under specific pathogen-free conditions. Germ-free $C d 1 d^{-/}$mice exhibited a defect in Paneth cell granule ultrastructure and ability to degranulate after bacterial colonization. In vitro, NKT cells were shown to induce the release of lysozyme from intestinal crypts. Together, these data support a role for Cd1d in regulating intestinal colonization through mechanisms that include the control of Paneth cell function.
\end{abstract}

\section{Introduction}

The mammalian intestine contains a highly complex ecology of microorganisms whose composition is critical to, on the one hand, establishing tissue homeostasis and, on the other, contributing to immune-mediated pathologies. Almost all of these bacteria accumulate within the colon, whereas colonization of the small intestine is very limited, suggesting that powerful host mechanisms exist to exclude and/or limit bacteria from this site. Although increasing knowledge is available on genetically predetermined host responses to intestinal microbes, there is less understanding about how bacterial commensalism is established in mammalians and what host factors specifically contribute to this process $(1,2)$. Bacteria that are destined to colonize the intestines interact with the host at a variety of levels. At the cellular level, the major cell types involved include intestinal epithelial cells (IECs) and hematopoietic cells, which interact with and respond to the bacteria in an integrated fashion through a variety of pathways that are associated with innate and adaptive immune functions (3). Hematopoietic cells, and in particular B lymphocytes, respond with the production of commensal bacteria-specific immunoglobulins of

Authorship note: Edward E.S. Nieuwenhuis and Tetsuya Matsumoto contributed equally to this work

Conflict of interest: The authors have declared that no conflict of interest exists.

Nonstandard abbreviations used: $\alpha$ GalCer, $\alpha$-galactosylceramide; IEC, intestinal epithelial cell; $\alpha$ ManCer, $\alpha$-mannosylceramide; Pc, Paneth cell; qPCR, quantitative PCR; SFB, segmented filamentous bacteria; SPF, specific pathogen-free. Citation for this article: J. Clin. Invest. 119:1241-1250 (2009). doi:10.1172/JCI36509. the IgA class that serves to limit bacterial translocation across epithelial cells $(3,4)$. IECs can regulate mucosal homeostasis by responding to ligands from the subcellular components of bacteria through the expression of TLRs (5).

One type of differentiated epithelial cell that is of particular interest is the Paneth cell $(\mathrm{Pc})$ that resides in the intestinal crypt. Pcs secrete a variety of antibacterial proteins called cryptdins (or $\alpha$-defensins) into the intestinal lumen (6). Caudal, an intestinal homeobox gene in Drosophila, which regulates antimicrobial peptide expression in a NF- $\mathrm{KB}$ dependent pathway, has recently been identified as a host factor that is responsible for regulating commensalism with gut microbiota (2). As previously suggested, this raises the possibility that the antimicrobial activities of Pcs might play a role in the regulation of mucosal colonization $(7,8)$. Pcs have also previously been noted to be a site of Cd1d expression in mice (9). In addition to the Pc, CD1D, a MHC class I-related protein, is constitutively expressed on both IECs (10-13) and hematopoietic cells (14). CD1D functions in the presentation of glycolipid antigens to CD1D-restricted T cells, so-called NKT cells, which rapidly release significant quantities of cytokines and other mediators upon CD1D recognition $(15,16)$. The recognition of glycolipid antigens by NKT cells plays an important role in antimicrobial defense, in that, NKT cells regulate a variety of bacterial, fungal, and viral pathogens, including those that originate in mucosal tissues such as the lung and intestine (17). Although the glycolipid antigens that activate NKT cells for antimicrobial defense are only incompletely known, they include both pathogenderived lipids and host-derived lipids that are microbially induced 

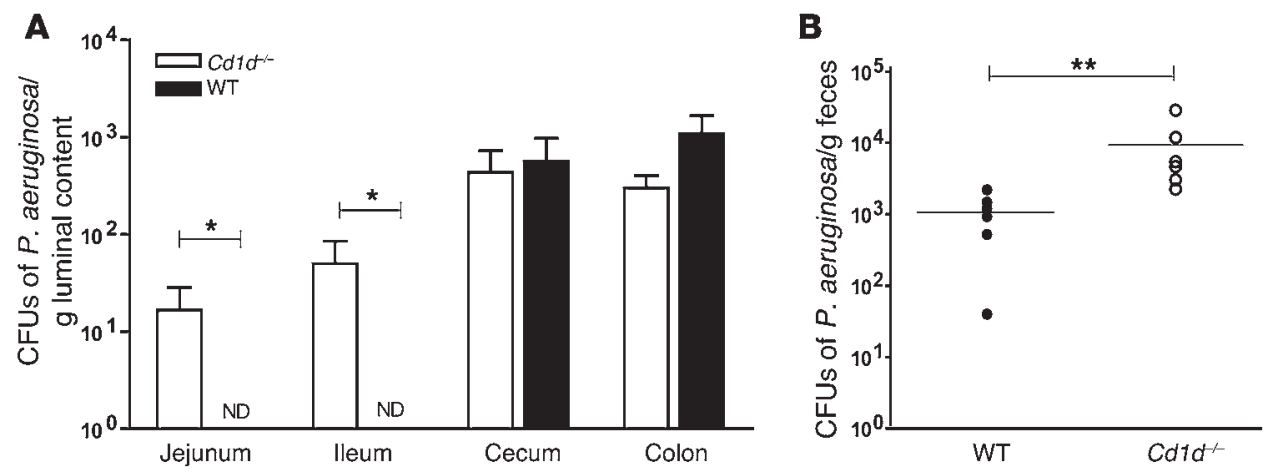

\section{Figure 1}

Colonization of the small intestine of $C d 1 d^{-/-}$SPF C57BL/6 mice, 12 hours and 12 days after oral inoculation of a single dose of $P$. aeruginosa strain D4 using orogastric gavage. (A) The viable number of bacteria was determined 12 hours after inoculation with $4 \times 10^{7} \mathrm{CFU}$ of $P$. aeruginosa per mouse, by culturing the luminal contents obtained from each part of the intestine on selective media for $P s e u d o m o n a s ~ s p$. $(n=5$ for each group; ${ }^{*} P<0.05$; ND, not detectable, i.e., $<10 \mathrm{CFU} / \mathrm{g}$ ). (B) Oral inoculation with $10^{8} \mathrm{CFU}$ of $P$. aeruginosa strain D4 per mouse once a day for 3 days. Fecal samples were obtained 12 days after inoculation (individual data [symbols] and mean [horizontal lines] are indicated; probabilities were calculated by Student's $t$ tests; $n=6$ for each group; ${ }^{\star *} P<0.01$ ). Data represent mean \pm SEM.

(18-20). CD1D is also capable of reverse signaling in epithelial (21) and hematopoietic cells (22), raising the possibility that NKT cells may also elicit effector cell functions from CD1D-bearing antigenpresenting cells. The cellular locations of CD1D expression in the intestine and the known role of CD1D in microbial host defense prompted us to examine the role of CD1D in regulating the normal colonization of the intestine. We show that colonization of the intestine with a pathogen (Pseudomonas aeruginosa), a provisional pathogen (Staphylococcus aureus), or 2 commensal bacteria (E. coli and Lactobacillus gasseri) is regulated by $\mathrm{Cd} 1 \mathrm{~d}$.

\section{Results}

Colonization of the small intestine is Cd1d dependent. We have previously shown that Cd1d-deficient mice exhibit increased colonization of the lung with a human pathogenic strain of $P$. aeruginosa (23). Therefore, we determined the degree of colonization with $P$. aeruginosa of specific pathogen-free (SPF) mice at various sites within the intestine at 12 hours after oral inoculation with $4 \times 10^{7}$ CFUs $P$. aeruginosa per mouse. At this time point, similar quantities of $P$. aeruginosa were present within the cecum and colon of WT and $C d 1 d^{-/-}$mice (Figure 1A). In contrast, although no evidence of $P$. aeruginosa could be detected within the jejunum and ileum of WT mice, $C d 1 d^{-/-}$mice contained approximately $10^{2}$ $\mathrm{CFU} / \mathrm{g}$ of $P$. aeruginosa within the small intestine (Figure $1 \mathrm{~A})$. To confirm this result and to show whether these differences in colonization of the small and large intestine with $P$. aeruginosa were physiologically relevant to the total microbial ecology of the mouse, we inoculated mice with $10^{8}$ CFUs of $P$. aeruginosa once a day for 3 days using gastric gavage and quantified the concentrations of $P$. aeruginosa in the feces. At 12 days after inoculation, we detected an increased quantity of CFUs of $P$. aeruginosa within the feces of $C d 1 d^{-/-}$mice in comparison to WT mice (Figure $1 \mathrm{~B}$ ). These studies indicated that in the absence of Cd1d, overgrowth of bacteria occurs specifically within the small intestine. To confirm this, we applied a pre-

\section{Figure 2}

viously established small intestinal overgrowth model (24). In this model, oral treatment of mice with vancomycin is associated with overgrowth of vancomycin-resistant Gram-negative bacteria in the ileum. This treatment was applied to mice at 3 weeks after colonization with $P$. aeruginosa, and $C d 1 d^{-/-}$mice exhibited a significantly increased rate of small intestinal overgrowth with P. aeruginosa (Supplemental Figure 1; supplemental material available online with this article; doi:10.1172/JCI36509DS1). These studies revealed that a Cd1d-dependent pathway exists within the small intestine that regulates mucosal colonization with a Gramnegative pathogenic bacterium.

Prevention of intestinal colonization with P. aeruginosa or E. colithrough $C d 1 d$-restricted NKT cell activation. Because clearance of $P$. aeruginosa from the small intestine was decreased in C57BL/6 $\mathrm{Cd} 1 \mathrm{~d}^{-/-}$mice,
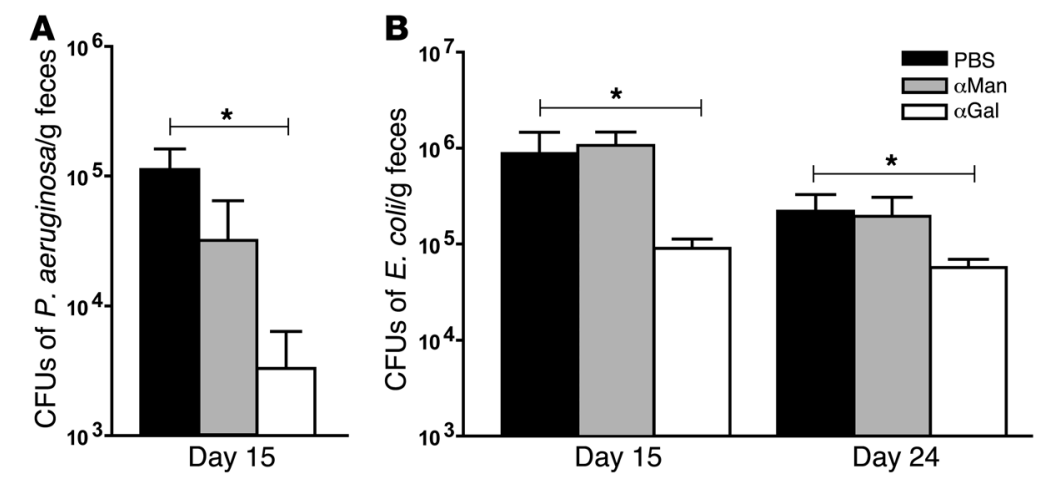

Prevention of intestinal colonization with $P$. aeruginosa or $E$. coli through $C \mathrm{~d} 1 \mathrm{~d}-$ restricted NKT cell activation. SPF BALB/c mice were treated with streptomycin sulfate (added to the drinking water at $1 \mathrm{mg} / \mathrm{ml}$ ) from days 1 to 5 . At days 2, 4, 6, 8, and 10 , mice received an intraperitoneal injection with $2 \mu \mathrm{g} \alpha \mathrm{GalCer}(\alpha \mathrm{Gal})(\mathrm{KRN} 7000)$, $2 \mu \mathrm{g} \alpha$ ManCer ( $\alpha$ Man), or PBS. From days 6 to 10, P. aeruginosa strain D4 (A) or E. coli strain ATCC 25922 (B) were added to the drinking water at $10^{5} \mathrm{CFU} / \mathrm{ml}$. Fecal samples from each group of mice were obtained at days 15 (A) and 15 and 24 (B) and cultured on gentamicin-containing plates after serial dilution with sterile saline (data are mean \pm SEM; probabilities were calculated by Student's $t$ tests; $n=6$ for each group; $\left.{ }^{*} P<0.05\right)$. 
A

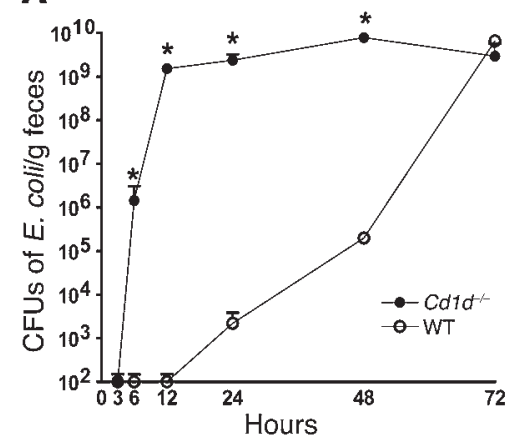

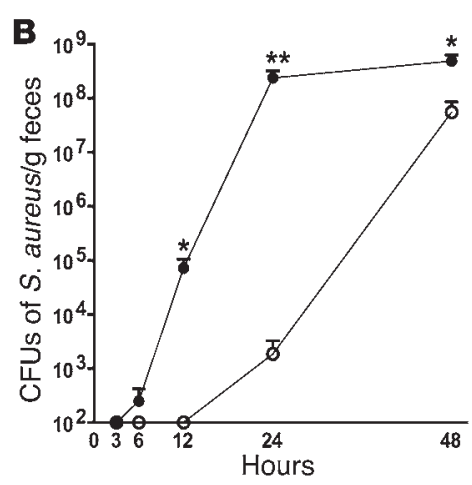

C

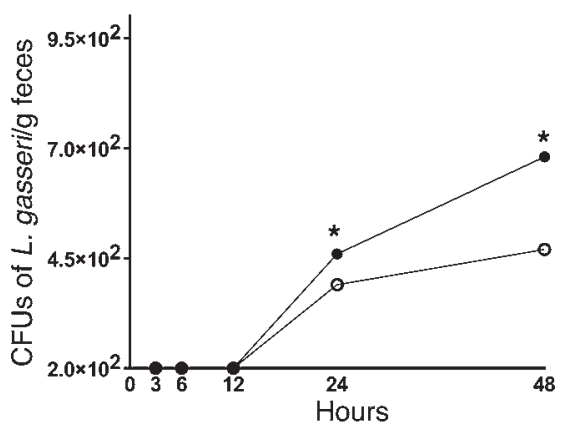

Figure 3

Accelerated intestinal colonization with E. coli, S. aureus, and L. gasseri in Cd1d ${ }^{-1-}$ BALB/c mice. (A) Germ-free Cd1d ${ }^{-/-}$mice and WT BALB/C mice were orally inoculated $650 \mathrm{CFUs}$ of $E$. coli strain ATCC 25922. Fecal samples from each group of mice were obtained at indicated time points after inoculation and cultured after serial dilution with sterile saline (data represent mean $\pm \mathrm{SEM} ; n=4$ for each group; $\left.{ }^{*} P<0.05\right)$. (B) Germ-free $C d 1 d^{-/-}$mice and WT BALB/c mice were orally inoculated with 10 CFUs of $S$. aureus strain ATCC 25923 (data represent mean \pm SEM; $n=6$ for each group; ${ }^{*} P<0.05,{ }^{* *} P<0.01$ ). (C) Germ-free $C d 1 d^{-1-}$ mice and WT BALB/c mice were orally inoculated with $10 \mathrm{CFUs}$ of $L$. gassseri strain ATCC 33323. Fecal samples were obtained at various time points after inoculation and cultured after serial dilution with sterile saline (data represent mean \pm SEM; $n=6$ for each group; $\left.{ }^{*} P<0.05\right)$.

we sought to determine whether the corollary activation of Cd1d-restricted T cells could increase $P$. aeruginosa clearance and diminish mucosal colonization with this bacterium. We therefore activated NKT cells by administration of the Cd1d-restricted model glycolipid antigen $\alpha$-galactosylceramide ( $\alpha$ GalCer) to SPF WT mice prior to $P$. aeruginosa colonization (23). After inoculation with $P$. aeruginosa, $\alpha$ GalCer-treated animals, but not animals treated with the nonfunctional glycolipid analogue $\alpha$-mannosylceramide ( $\alpha$ ManCer), exhibited fewer viable $P$. aeruginosa within the intestine as defined by the quantities of $P$. aeruginosa detectable within feces (Figure 2A). Importantly, these effects of Cd1d activation on intestinal colonization with $P$. aeruginosa occurred without any detectable changes on mucosal morphology as determined by histology (data not shown). To further determine whether this effect of Cd1d-specific activation could also extend to other Gram-negative bacteria, we colonized SPF mice with a nonpathogenic strain of (gentamicin-resistant) E. coli. As shown in Figure 2B, similar treatment of mice with $\alpha$ GalCer, but not $\alpha$ ManCer, resulted in a limited ability of the administered $E$. coli to establish colonization within the intestine. As $P$. aeruginosa is not known to be a common constituent of the normal intestinal microbiota, the experiments with the E. coli strain, as applied here, suggest that $\mathrm{Cd} 1 \mathrm{~d}$ is, in fact, actively involved in regulating intestinal colonization with commensal bacteria.

Enhanced intestinal colonization with E. coli, S. aureus, and L. gasseri in $C d 1 d^{-/}$mice. The normal intestine contains a complex microbial ecosystem of more than 800 strains of bacteria that reach concentrations of more than $10^{12} \mathrm{CFU} /$ gram of feces. As a result, the performance of colonization studies under SPF conditions does not allow for a direct demonstration that the effects of Cd1d deletion occur specifically on the colonizing bacterium. Therefore, we examined 3 colonization models in mice raised under germ-free conditions. Germ-free mice were orally inoculated with $650 \mathrm{CFUs}$ of E. coli, and fecal samples were obtained at the indicated time points to examine the rate of colonization. In WT mice, the levels of E. coli were observed to gradually increase and became detectable within the feces by 12 hours after inoculation (Figure 3A). Subsequently, the bacterial growth rate rapidly increased to reach peak levels of $10^{10} \mathrm{CFUs}$ of $\mathrm{E}$. coli/g feces at 72 hours, concentrations of bacteria typical of a conventionally reared animal. Strikingly, $\mathrm{Cd} 1 d^{-/}$mice displayed a completely different pattern of intestinal colonization. By 6 hours after inoculation, the second time point measured, Cd1 $1 d^{-/}$mice were already colonized with $10^{6} \mathrm{CFUs}$ of $\mathrm{E}$. coli/g feces. By 12 hours, the bacterial concentrations were equivalent to the steady-state levels observed in WT animals after 72 hours of colonization and represented $10^{9} \mathrm{CFUs}$ of E. coli/g feces. In comparison, at 12 hours, WT mice exhibited barely detectable quantities of bacteria within the feces. The $10^{9}$-fold difference detected in faecal CFUs of the $E$. coli strain examined at this early time point demonstrates a direct and critical involvement of $\mathrm{Cd} 1 \mathrm{~d}$ in the prevention of intestinal colonization with a commensal, Gram-negative bacterium. As shown in Table 1, this degree of intestinal colonization was clinically relevant, since translocation of $E$. coli to the mesenteric lymph nodes was only observed in $C d 1 d^{-/-}$but not WT mice. These latter results further suggested that $\mathrm{Cd} 1 \mathrm{~d}$ is not only involved in the regulation of mucosal colonization but also in preventing the passage of viable bacteria across an anatomically intact intestinal barrier. To determine whether Cd1d-dependent regulation of mucosal colonization with bacteria also extends to Gram-positive bacteria, a simi-

\section{Table 1}

Translocation of $E$. coli into the mesenteric lymph nodes of Cd1 $1^{-1-B A L B} / \mathrm{c}$ mice

\begin{tabular}{lcccc}
\hline & Liver & Spleen & MLNs & Blood \\
$C d 1 d^{--}$ & ND & ND & $1,125 \pm 750^{A}$ & ND \\
WT & ND & ND & ND & ND \\
\hline
\end{tabular}

Germ-free Cd1 $d^{-/-}$mice $(n=4)$ and WT BALB/c mice $(n=5)$ were orally inoculated with 650 CFUs per mouse of $E$. coli strain ATCC 25922. Mice were sacrificed at 4 days after inoculation and blood, liver, mesenteric lymph nodes (MLNs), and spleen were collected aseptically and cultured for the presence of $E$. coli. ${ }^{A} P<0.05$. ND, not detected $(<100 \mathrm{CFU} / \mathrm{g}$ for liver, spleen, mesenteric lymph nodes; <10 CFU/ml for blood). 
A

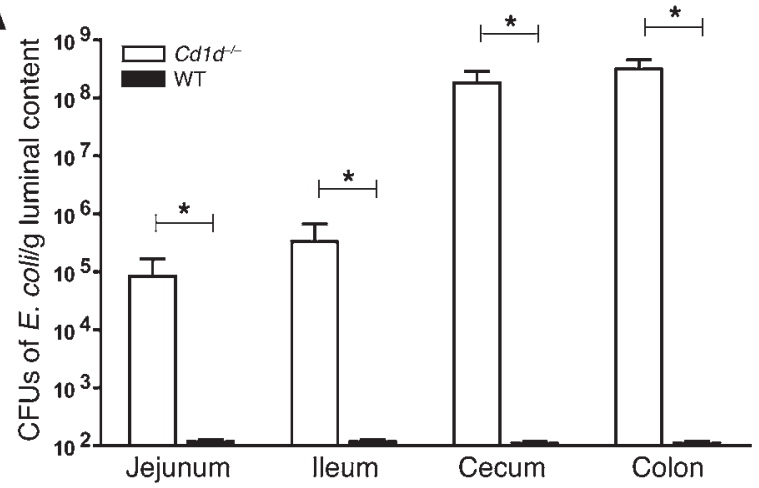

B

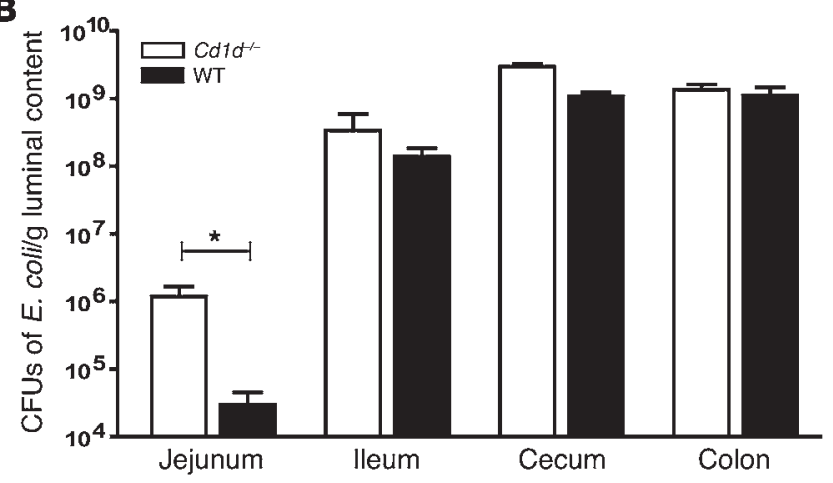

C

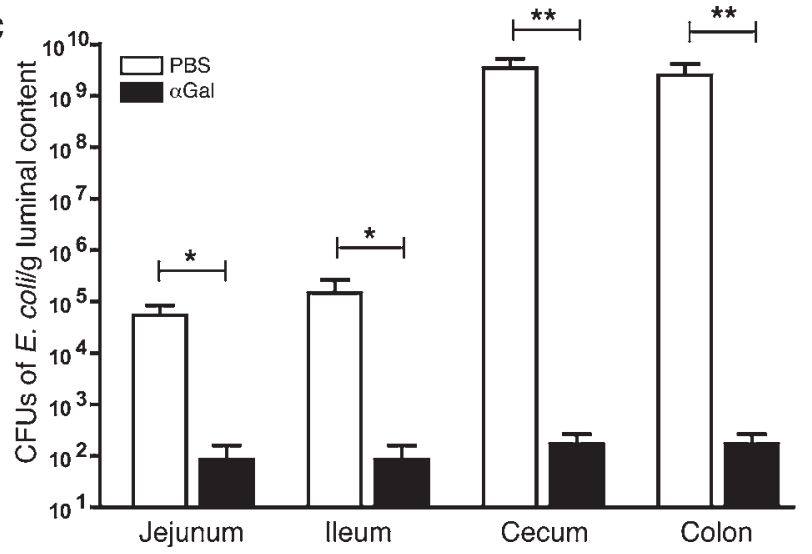

lar experimental approach was pursued with S. aureus. Germ-free mice were therefore orally inoculated with $10^{1} \mathrm{CFUs}$ of $S$. aureus. As observed with E. coli, a strong enhancement and rate of bacterial colonization was detectable in $\mathrm{Cd} 1 d^{-/-}$mice in comparison to WT mice (Figure 3B). Next, we inoculated germ-free mice with $10^{1}$ CFUs of L. gasseri. Although Lactobacillus spp. grow relatively slowly, we were still able to detect enhanced colonization of this bacterium within the intestines of $C d 1 d^{-/}$at 24 and 48 hours (Figure 3C). These data indicated that the role of Cd1d in regulating mucosal colonization is not limited to Gram-negative bacteria but extends to Gram-positive species.

To ascertain whether the site of $\mathrm{Cd} 1 \mathrm{~d}$-mediated regulation of mucosal colonization with bacteria was predominantly contained within the small intestine, as suggested in the studies of $P$. aeruginosa under SPF conditions, we examined the colonization of germfree mice at different locales within the intestinal axis. Germ-free mice were inoculated with a very low dose of E. coli and the lumi-

\section{Figure 4}

Enhanced intestinal colonization with $E$. coli of $C d 1 d^{-/-}$BALB/c mice within the entire intestine at $t=12$ hours and within the jejunum at $t=120$ hours and prevention of intestinal colonization with $E$. coli through Cd1d-restricted NKT cell activation. (A) Germ-free Cd1d $d^{-/}$ $B A L B / c$ mice and WT BALB/c mice were orally inoculated with 50 CFUs per mouse of $E$. coli strain ATCC 25922. The viable number of bacteria were determined by culturing the luminal contents that were obtained from each part of the intestine at 12 hours after inoculation (data represent mean \pm SEM; $n=6$ for each group; $\left.{ }^{*} P<0.05\right)$. (B) Germ-free Cd1 $1 d^{-/-}$mice $(n=4)$ and WT BALB/c mice $(n=5)$ were orally inoculated with 650 CFUs per mouse of E. coli strain ATCC 25922. The viable number of bacteria were determined by culturing the luminal contents that were obtained from each part of the intestine at $t=120$ hours after inoculation (data represent mean \pm SEM; $n=4$ or 5 for each group; ${ }^{\star} P<0.05$ ). (C) Each germ-free WT mouse was treated intraperitoneally with $2 \mu \mathrm{g}$ of $\alpha \mathrm{GalCer}$ or PBS. Subsequently, mice were inoculated with 65 CFUs per mouse of $E$. coli strain ATCC 25922. At 24 hours after inoculation, the viable number of bacteria were determined by culturing the luminal contents that were obtained from each part of the intestine (data are mean \pm SEM; probabilities were calculated by Student's $t$ tests; $n=6$ for each group; $\left.{ }^{\star} P<0.05,{ }^{* *} P<0.005\right)$.

nal contents of the intestines of these animals were cultured at a very early time point ( $t=12$ hours after inoculation) and a late time point $(t=120$ hours after colonization). As shown in Figure 4A, E. coli was barely detectable at any location within the small or large intestine of WT mice at 12 hours after inoculation. In contrast, $C d 1 d^{-/-}$mice exhibited a substantial degree of intestinal colonization with E. coli at every site examined. Consistent with the observation that the small intestine is the predominant site of Cd1d-mediated regulation of microbial colonization, at 120 hours after colonization, when steady-state levels of bacteria would be expected to be achieved based upon previous studies reported above (Figure 3), significant differences in colonization were persistently detectable in the proximal small intestine (jejunum) but not within the ileum, cecum, or colon (Figure 4B). In comparison, activation of Cd1d-restricted $T$ cells by a single dose of $\alpha \mathrm{GalCer}$ prior to E. coli colonization of germ-free WT mice was associated with almost complete prevention of intestinal colonization at 24 hours after inoculation (Figure 4C). These latter studies indicated that mice are capable of eradicating and/or preventing colonization of the intestine with $E$. coli only in the presence of Cd1d. Taken together, these studies indicated the presence of a Cd1d-restricted pathway of mucosal resistance to microbial colonization within the intestine that is effectively operative in the small intestine.

Cd1d deficiency is associated with alterations in the composition of the commensal microbiota. These studies suggested that in the absence of normal Cd1d function, a defect in microbial clearance existed, which emanated from the small intestine and extended distally into the colon. We therefore examined whether this defect in regulation of the microbiota that was evident in Cd1d-deficient mice could be detected among the commensal microbiota in mice under SPF conditions. To this aim, we assessed the morphology of the microbial communities within the small intestine of WT and $C d 1 d^{-/}$mice by using FITC-labeled oligonucleotide probes that recognize the majority of murine intestinal bacteria (Figure 5). Using this method, we were able to confirm the presence of various microbial species in close proximity to the small intestinal villi in $C d 1 d^{-/}$mice that were absent in WT mice. In particular, we were 
A

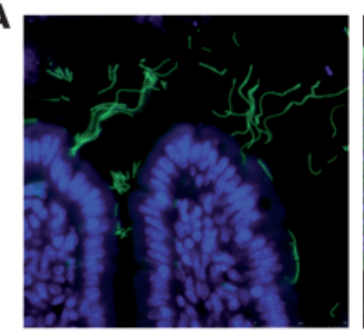

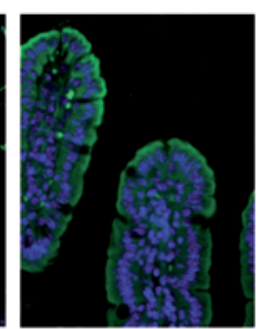

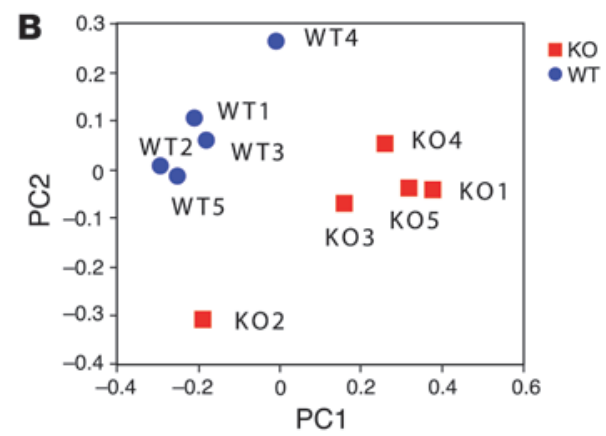

Figure 5

Fluorescent in situ hybridization on mouse ileal sections with a specific probe (SFB1008). (A) Cd1 $d^{-/-}$ mice exhibit SFB in close proximity to small intestinal villi (left panel) that is absent in WT mice (right panel). Original magnification, $\times 60$. (B) $16 \mathrm{~S}$ rRNA sequence analysis of fecal samples shows that $\mathrm{Cd}_{1 \mathrm{~d}^{-1-}}(\mathrm{KO})$ mice are colonized with distinct clusters of microbial communities in comparison to WT littermates. Samples were positioned in relation to principal coordinates (PC1 and PC2) based on the sequence similarity between $16 \mathrm{~S}$ data.

able to identify segmented filamentous bacteria (SFB) among the specific colonizers of the small intestine in $\mathrm{Cd} 1 \mathrm{~d}^{-/-}$mice (Figure $5 \mathrm{~A}$, left panel) but not WT mice (Figure 5A, right panel). In addition, we examined $16 S$ rRNA sequences obtained from intestinal microbes contained within the feces of WT and $\mathrm{Cd} 1 d^{-/-}$mice. As it has been shown that genetically identical mice reared in different facilities may be inhabited by different microbial populations, we used littermates derived from a heterozygous breeding pair that were raised in the same cage (25). A total of 811 bacterial near-fulllength $16 \mathrm{~S}$ rRNA sequences were subjected to phylogenetic analysis (26-28). These studies established that $C d 1 d^{-/-}$mice are colonized with clusters of microbial communities that are distinct from those present in WT mice (Figure 5B and Supplemental Table 1). These studies showed that $\mathrm{Cd} 1 \mathrm{~d}$ deficiency results in alterations of the overall composition and architecture of the commensal microbiota contained within the murine intestine.

Profound morphological and functional differences in Pc granule composition in $\mathrm{Cd} 1 \mathrm{~d}^{-/-}$mice and upon NKT cell activation. Based upon the fact that the differences in colonization between WT and $C d 1 d^{-/-}$mice appeared to originate from the small intestine and because this regulation occurred at very early periods of time after inoculation, we further focused on Pcs. Pcs are found only in the bases of the crypts of Lieberkühn located within the small intestine. Pcs contain secretory granules that are packed with lysozyme and other antibacterial enzymes such as $\alpha$-defensins and zinc and are known to protect the host from the pathogenic invasion of microorganisms such as Salmonella sp (29). Upon exposure to the products of bacteria and other secretagogues, Pcs rapidly secrete the contents of these granules and other antimicrobial molecules into the crypt lumen, thereby contributing to a potential first-line of intestinal antimicrobial defense $(30,31)$. As such, we hypothesized that the antimicrobial defense provided by these cells is dependent on Cd1d and/or Cd1d-restricted NKT cell activation and linked to the homeostatic regulation of mucosal colonization and the establishment of bacterial commensalism.

The initial analysis of fixed intestinal tissues from germ-free and SPF mice stained with hematoxylin and eosin did not reveal any significant differences in either the number of Pcs or the quantity of granules per Pc when WT mice and $C d 1 d^{-/-}$animals were compared (Supplemental Figure 2A). Next, we examined lysozyme-p the amount of lysozyme immunoreactivity in $C d 1 d^{-/-}$animals was similar to that of WT animals prior to colonization (Figure 6A, top panels), a decrease in lysozyme staining intensity after colonization was not detectable in the $C d 1 d^{-/-}$mice (Figure 6A, bottom panels). To confirm that the detected differences represented a defect in Cd1d-restricted microbial-induced degranulation, germ-free $C d 1 d^{-/-}$mice were subjected to challenge with pilocarpine, a known Pc secretagogue. C $d 1 d^{-/-}$mice exhibited normal Pc degranulation relative to WT animals at 30 minutes after in vivo treatment with pilocarpine (Figure 6A, middle panels).

The aforementioned studies suggested that Pc function was regulated by Cd1d. We therefore performed a series of ex vivo experiments to directly establish whether activation of NKT cells could result in Pc activation. In order to do so, we isolated small intestinal crypts that were obtained from WT mice (29). Subsequently, these crypt cell preparations were incubated with an invariant mouse NKT cell line (DN32), with or without $\alpha$ GalCer. When the crypt cell preparations were co-incubated with NKT cells and $\alpha G a l C e r$, rapid release of lysozyme-p was observed, but this did not occur in the presence of either NKT cells or $\alpha$ GalCer alone (Figure $6 \mathrm{~B})$. Similarly, treatment of WT mice (BALB/c) with $\alpha$ GalCer was associated with a Pc appearance consistent with degranulation, as revealed by multiple empty granules with decreased lysozyme immunoreactivity along the crypt axis (Figure 6C). Notably, no changes in lysozyme immunoreactivity were detected when $\mathrm{Cd} 1 \mathrm{~d}^{-/-}$ mice were treated with $\alpha$ GalCer, confirming the requirement of Cd1d to activate NKT cells by $\alpha$ GalCer (Supplemental Figure 3 ).

Taken together, these studies indicated that Cd1d-restricted mechanisms are involved in regulating Pc function and that this Cd1d-mediated pathway is operative during and effective in regulating bacterial colonization. Given the absence of a decrease in lysozyme staining intensity in Pcs after bacterial colonization of $C d 1 d^{-/-}$mice, we also considered the possibility that $\mathrm{Cd} 1 \mathrm{~d}$ controls not only the ability of the Pc to extrude granule contents but also the composition of Pc-associated granules. We therefore further studied the nature of the granules present in germ-free $C d 1 d^{-/-}$mice by using light microscopic morphometry, electron microscopy, and immunohistochemistry. As shown in Figure 6D, the Pcs of $C d 1 d^{-/-}$mice exhibited predominantly smaller Pc granules, whereas granules of larger size were nearly completely absent 
A
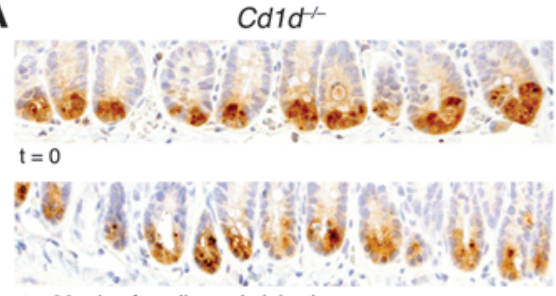

$\mathrm{t}=30 \mathrm{~min}$ after pilocarpin injection

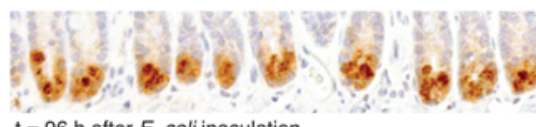

$\mathrm{t}=96 \mathrm{~h}$ after $\mathrm{E}$. coli inoculation

C

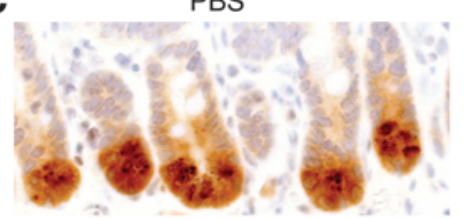

$\alpha \mathrm{Gal}$

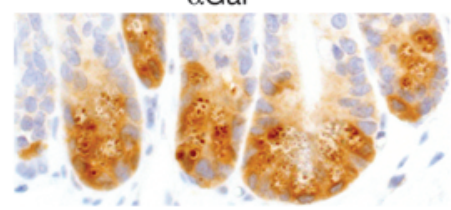

WT
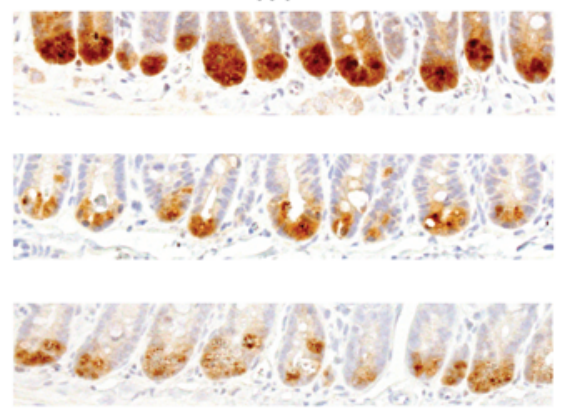

B

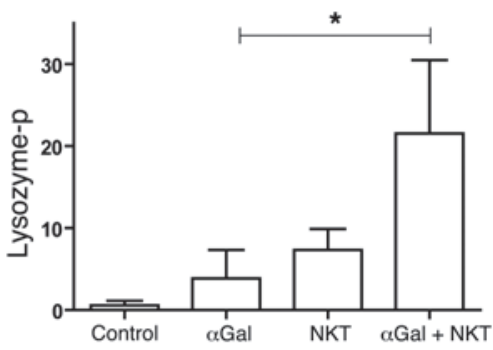

D

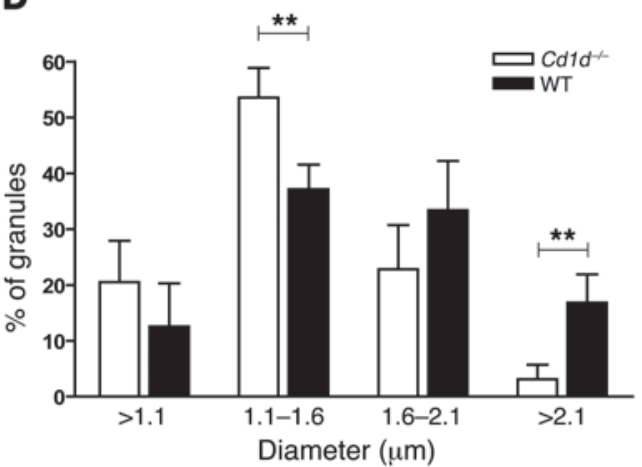

E

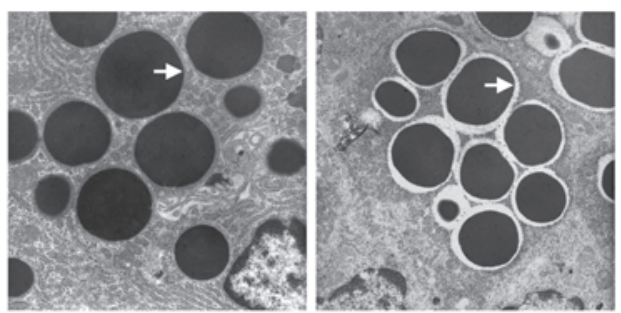

$\mathbf{F}$
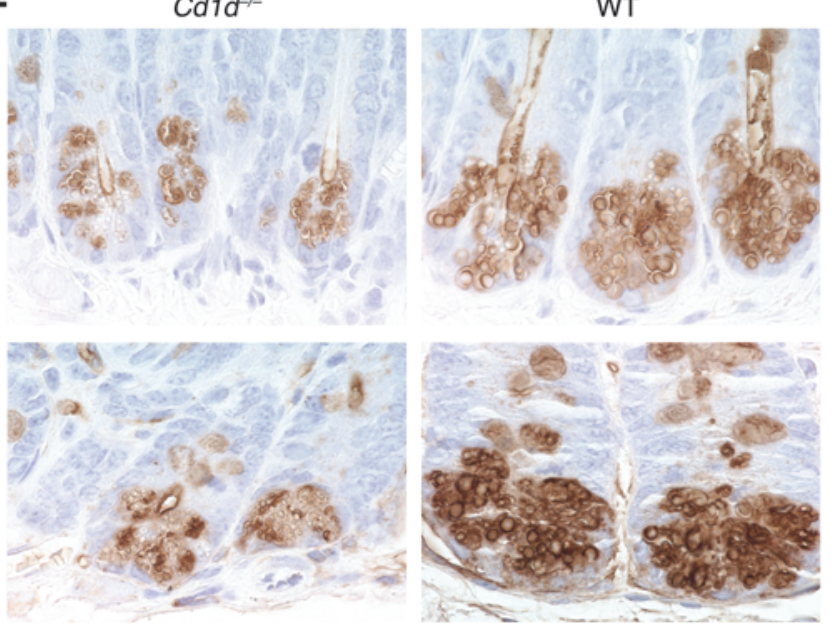

\section{Figure 6}

Morphological and functional differences of Pc granules in Cd1 $d^{-1-}$ mice and upon NKT cell activation. (A) Decreased lysozyme-p immunoreactivity in jejuno-ileal sections of WT mice (right panels) at $t=96$ hours (bottom panel) of colonization with $E$. coli compared with baseline levels (top panel), which is absent in $\mathrm{Cd} 1 \mathrm{~d}^{-/-}$animals (left panels). Germ-free $\mathrm{C} d 1 \mathrm{~d}^{-/-}$mice exhibited normal Pc degranulation relative to WT animals at 30 minutes after in vivo treatment with pilocarpine $(2.0 \mathrm{mg} / \mathrm{mouse})$. (B) Coincubation of crypt preparations with $\alpha \mathrm{GalCer}$ and DN32 cells results in lysozyme-p release, expressed as a ratio of the optical intensity for lysozyme-p/optical intensity for $\beta$-actin in the pellet $\times 100$. (C) Mice exhibit empty granules, with enhanced lysozyme immunoreactivity along the crypt axis at 24 hours of intraperitoneal injection with $2 \mu \mathrm{g} \alpha \mathrm{GalCer}$, which are absent in PBS-treated mice. (D) Compared to WT mice, Pcs of $C d 1 d^{-/-}$mice exhibit smaller granules. (E) WT Pc granules have an electron-dense inner domain and a halo of intermediate density (left panel, arrow). In contrast, in Cd1d $d^{-/-}$mice, the peripheral halo is devoid of electron-dense material (right panel, arrow). (F) Histochemical staining with HRP-labeled lectins (Helix pomatia, top panel; Triticum vulgaris, bottom panel) reveals an altered oligosaccharide composition in Pc granules in $\mathrm{Cd1} 1 d^{-1-}$ mice (left panels). Original magnification, $\times 20(\mathbf{A}) ; \times 40$ (C); $\times 9,000(\mathbf{E}) ; \times 60(\mathbf{F})$. Data represent mean \pm SEM (B and D); ${ }^{\star} P<0.05,{ }^{\star \star} P<0.01$. 
in comparison to WT mice. Notably, these differences between WT and $C d 1 d^{-/-}$mice increased when germ-free mice were colonized with E. coli or when mice were raised under SPF conditions (Supplemental Figure 4). Consistent with this difference in granule size observed in $C d 1 d^{-/-}$mice, we detected a major difference in the ultrastructural composition of the granules contained in these mice. The ultrastructural features of $\mathrm{Pc}$ granules are typically characterized by a peripheral halo of variable thickness and intermediate density, surrounding a large electron-dense core (32). Recently, it has been suggested that the peripheral halo mainly contains O-linked oligosaccharides with $\mathrm{N}$-acetyl-galactosamine (GalNAc) and N-acetyl-D-glucosamine (GlcNAc) residues and $\mathrm{N}$-linked oligosaccharides with GlcNAc residues (33). The peripheral Pc halo also contains the antimicrobial DNase I that is specifically associated with the exocrine secretory granules (34). The characteristic peripheral intermediately dense halo (Figure 6E, left panel, arrow) characteristic of WT animals was completely absent in the Pc granules of germ-free $\mathrm{Cd}_{1} d^{-{ }^{-}}$mice and instead an "empty" halo remained (Figure 6E, right panel, arrow). Finally, histochemical staining with HRP-labeled lectins (Helix pomatia and Triticum vulgaris lectin) revealed an altered oligosaccharide composition of Pc granules obtained from Cd1 $1 d^{-/-}$mice (Figure 6F). Our studies thus indicated that $\mathrm{Cd} 1 \mathrm{~d}$ controls both the composition of Pc granules, particularly the composition of the peripheral halo, and their degranulation after microbial colonization.

\section{Discussion}

The mucosal surfaces of the small intestine contain a surprisingly low abundance of commensal bacteria in comparison to the colon. Many physiochemical factors that contribute to this microbial homeostasis have been identified and include intestinal motility and the secretion of digestive juices, such as acid from the stomach, which in their absence leads to bacterial overgrowth and/or increased susceptibility to bacterial pathogens. A biochemical barrier also exists by means of various antimicrobial molecules secreted by Pcs located at the base of the small intestinal crypts of Lieberkühn. Specifically, Pc activation is associated with the degranulation of secretory granules and the release of antimicrobial peptides into the small intestinal crypts. Secretion can be attained in various ways, including cholinergic stimulation and exposure to bacterial antigens (29). Our studies demonstrate an important physiological role for a host cell immune factor, Cd1d, in regulating colonization of the intestine and consequently the establishment of commensalisms with Gram-negative (P. aeruginosa, E. coli) and Gram-positive (S. aureus, L. gasseri) bacteria. As a consequence, Cd1d-deficient mice were observed to have an alteration in the composition (based upon analysis of $16 S$ rRNA sequences) and architecture (based upon fluorescent in situ hybridization analysis) of the intestinal microbiota, with increased quantities of adherent bacteria. We hypothesize that this pathway of Cd1ddependent regulation of bacterial colonization is in part mediated by Pcs through the ability of Cd1d to affect Pc granule composition and/or the ability of Pcs to extrude lysozyme after bacterial colonization. Consistent with the primary location of Pcs, this function of $\mathrm{Cd} 1 \mathrm{~d}$ is mainly localized within the small intestine. The pathway of Cd1d-restricted regulation of Pc structure and function and, thus, mucosal colonization is initiated early after exposure of the intestine to bacteria. Although our in vitro studies suggested that Cd1d expression by Pcs is involved in these pathways, other mucosal Cd1d-bearing antigen-presenting cells, such as intestinal dendritic cells, might also contribute. Furthermore, it is possible that Cd1d-restricted responses may affect the antimicrobial function of epithelial cell types other than Pcs. As such, we have shown that absorptive epithelial cells can present glycolipid antigens to NKT cells, and it is known that IECs are able to produce cathelicidin-related antimicrobial peptides that may affect microbial colonization of the intestines (11).

Previously, it has been shown that cross talk between T lymphocytes within the intestinal lamina propria and the epithelial cells may regulate IEC differentiation (35). We, however, did not detect any differences in the quantities of Pc or the levels of lysozyme-p (Supplemental Figure 2B) and expression of CDX2 (36), a mammalian homologue of Caudal, using histochemistry (Supplemental Figure 2C) when we compared Cd1 $d^{-/}$and WT mice. Therefore, we hypothesize that $\mathrm{Cd} 1 \mathrm{~d}$-restricted regulation of Pcs does not involve their differentiation from stem cells but rather regulation of events distal to Pc differentiation, including Pc granule maturation and/or granule extrusion. The novel model that is described here has important implications for understanding the mechanisms by which the host regulates mucosal commensalism and thus the ability to manage microorganisms at the mucosal surfaces of the intestines.

These studies suggest that mucosal NKT cells may recognize lipid antigens that are induced by and/or associated with luminal bacteria, leading to the regulation of Pc function. In this respect, various bacterially derived lipids have been identified as Cd1drestricted antigens, such as Sphingomonas glycosphingolipids and Borrelia burgdorferi-derived diacylglycerols $(19,20,37)$. The variety of the bacteria that we used in our studies ( $P$. aeruginosa, E. coli, L. gasseri, and $S$. aureus) that seem to be regulated through this Cd1d-NKT cell-restricted mechanism, however, may indicate induction of a common endogenous antigen as being responsible for this mucosally associated process. Such endogenous antigens may include isoglobotrihexosylceramide (18), sulfatide (38), or others that are yet to be defined and may possibly include structures common to a variety of microbes.

These studies also potentially provide insight into the complex role that Cd1d-restricted NKT cells are thought to play in the pathogenesis of the inflammatory bowel diseases. It has been suggested that, in Crohn disease, polymorphisms of NOD2/CARD15, ATG16L1, or X-box binding protein 1 may result in Pc dysfunction, which leads to a failure to clear certain bacteria and, consequently, an uncontrolled mucosal innate and/or adaptive immune response (39-45). Previously, we and others have shown that Cd1d-restricted cells contribute to the histopathology associated with a murine model for ulcerative colitis $(46,47)$. These latter findings have been extended to human disease by showing that an atypical Th2 response that characterizes human ulcerative colitis is mounted by lamina propria Cd1d-restricted NKT cells (48). On the other hand, earlier studies in another mouse colitis model have suggested that Cd1d-restricted NKT cell activation with $\alpha$ GalCer or $\mathrm{OCH}$ can, in contrast, protect from colitis $(49,50)$. Taken together with the current findings, this protection may include activation of Pcs through NKT cell stimulation, resulting in diminished numbers of intestinal bacteria. In a corollary fashion, inadequate or dysregulated Cd1d-restricted T cell regulation of Pcs would be predicted to contribute to the development of colitis. This latter hypothesis is supported by recent reports on reduced expression of Pc defensins in Crohn disease, involving the ileum (44). Finally, a recent report established that the transcription factor $\mathrm{T}$ box expressed 
in $\mathrm{T}$ cells (T-bet) controls the host immune response to intestinal bacteria through regulation of TNF- $\alpha$ production. Specifically, it was shown that in mice that lack T-bet, intestinal bacteria become colitogenic and induce inflammation when transferred to genetically intact mice (51). These findings may point to some of the mechanisms through which mucosal NKT cells act as regulators of the relationship between the host and commensal bacteria.

In summary, Cd1d-restricted immune responses regulate mucosal commensalism and colonization of the intestines with pathogenic microorganisms in a pathway that involves Pcs. These observations reveal a direct role of the immune system in affecting the composition of luminal microbiota. As such, manipulation of Cd1d may offer a means to restrict mucosal exposure to invasive microorganisms or commensals to which pathogenic responses occur, such as in inflammatory bowel disease.

\section{Methods}

Animals. BALB/c and C57BL/6 mice were obtained from The Jackson Laboratories and Charles River Japan; 6- to 8-week-old male mice were used. $\mathrm{Cd} 1 d^{-/-}$mice (on BALB/c or C57BL/6 background) were used as described. All mice were maintained under SPF conditions or raised in germ-free conditions. All studies were approved by the Harvard Medical School Standing Committee on Animals. For the experiments associated with fluorescent in situ hybridization, $C d 1 d^{-/-}$mice were compared with aged-matched $\mathrm{C} 57 \mathrm{BL} / 6$ mice that were bred and reared in the same room for over 4 years. WT and $C d 1 d^{-/-}$mice, for the experiments involving an evaluation of $16 \mathrm{~S}$ rRNA analysis, were littermates that were reared in the same cages.

Bacterial strains and culture conditions. P. aeruginosa strain D4 is a nonmucoid, lipopolysaccharide-rough derivative of a mucoid isolate from a patient with pneumonia. An E. coli strain (ATCC 25922), a S. aureus strain (ATCC 25923), and a L. gasseri strain (ATCC 33323) were obtained from the ATCC. Bacteria were kept frozen at $-80^{\circ} \mathrm{C}$ in sterile vials (Microbank; ProLab Diagnostics) and freshly cultured for each experiment.

Reagents used for in vitro and in vivo experiments. $\alpha$ GalCer (KRN7000) and $\alpha$ ManCer were provided by Kirin Pharmaceuticals. Pilocarpine was purchased from Sigma-Aldrich.

Preparation of $16 S$ rRNA library and sequencing. The nearly full-length $16 S$ rRNA was amplified from extracted DNA using bacterial universal PCR primers Bact-27 forward (5'-AGRGTTTGATYMTGGCTCAG-3') and Bact1492 reverse (5'-GGYTACCTTGTTACGACTT-3'). Reaction conditions were as follows: $2.5 \mu \mathrm{l} 10 \mathrm{X}$ PCR buffer (Takara Bio), $2.5 \mu \mathrm{dNTP}(25.0$ $\mathrm{mM}$; Takara Bio), $0.5 \mu \mathrm{l}$ primer (10.0 pmol/ $\mu \mathrm{l}$ each), $0.1 \mu \mathrm{l}$ ExTaq DNA polymerase (5.0 U/ $\mu$ l; Takara Bio), $0.5 \mu$ l of template DNA, and DNase-free water $(18.4 \mu \mathrm{l})$ in a total volume of $50.0 \mu \mathrm{l}$. PCR was performed using a T1 Thermocycler (Biometra). The following cycling parameters were used: 30 seconds of initial denaturation at $96^{\circ} \mathrm{C}$, followed by 20 cycles of denaturation $\left(30\right.$ seconds at $\left.96^{\circ} \mathrm{C}\right)$, annealing $\left(20\right.$ seconds at $\left.56^{\circ} \mathrm{C}\right)$, and elongation $\left(90\right.$ seconds at $68^{\circ} \mathrm{C}$ ), with a final extension at $72^{\circ} \mathrm{C}$ for 10 minutes. Amplified products of nearly $1.5 \mathrm{~kb}$ in length were verified by gel electrophoresis, using $1 \mu \mathrm{l}$ of the PCR reaction mixture in $1.0 \%$ agarose gels. PCR products were ligated with PCR-4-TOPO vectors (Invitrogen) and transformed into DH12S competent E. coli cells (Invitrogen) using the TOPO-TA Cloning Kit (Invitrogen) to construct the $16 \mathrm{~S}$ rRNA library. Ninety-six colonies from the library were isolated randomly and subjected to colony PCR using primers M13 forward (5'-GTAAAACGACGGCCAG-3') and M13 reverse (5'-CAGGAAACAGCTATGAC-3') to amplify the insert $16 S$ rRNA genes, respectively. After PCR products were treated with Exonuclease I and Shrimp Alkaline Phosphatase (GE Healthcare), sequencing of both ends of DNA was done by using BigDye Terminator (Applied Biosystems) and 3.2 pM of T7 (5'-TAATACGACTCACTATAGGG-3') and T3 (5'-AATTAACCCTCACTA-
AAGGG-3') primers. Bact-357 forward (5'-CCTACGGGAGGCAGCAG-3') primer was also used for further sequencing of the middle region of $16 \mathrm{~S}$ rRNA. Sequencing products were purified by ethanol precipitation and run on automated ABI 3730-Capillary Sequencers (Applied Biosystems). Three reads, obtained from sequencing by T7, T3, and Bact-357 forward primers, were assembled with the Phred/Phrap program (26) for each $16 S$ rRNA to generate the high-quality sequence data.

Analysis of $16 \mathrm{~S} r \mathrm{rNA}$ sequences. The assembled $16 \mathrm{~S}$ rRNA sequences were aligned to each other with ClustalW analysis, and the multiple aligned sequences were calculated for the distance matrix of whole sequences. The operational taxonomic unit (OTU) calculation was performed with DOTUR (27), and the whole typical OTU sequences were aligned to the $16 S$ rRNA sequences of the Ribosomal Database Project II (RDP) database (http://rdp.cme.msu.edu/) in NCBI BLAST (http://www.ncbi.nlm. nih.gov/BLAST/). ClustalW analysis was applied to OTU sequences for calculating a phylogenetic tree, from which the neighbor-joining tree was obtained and was then sent to UniFrac (http://bmf2.colorado.edu/ unifrac/index.psp) (28) to determine the phylogenetic distance between each sample. Upon calculation of sequence $16 \mathrm{~S}$ similarity, samples were positioned in relation to principal coordinates (PC1 and PC2) based on the sequence similarity between $16 \mathrm{~S}$ data.

Fluorescent in situ bybridization on mouse intestinal tissue. Paraffin slides were deparaffinized and rehydrated. Slides were subjected to lysozyme treatment for 60 minutes $(20 \mathrm{mg} / \mathrm{ml}$ Tris-HCL, pH. 8.2; Sigma-Aldrich), washed in demineralized water, and dipped briefly in $96 \%$ ethanol. Once dry, a probe mixture containing $20 \mu \mathrm{l}$ FITC-labeled oligonucleotide general probe EUB338 or specific probe SFB1008 (Eurogentec) $(100 \mathrm{ng} / \mu \mathrm{l})$, $20 \mu \mathrm{l}$ Milli-Q (Millipore), and $160 \mu \mathrm{l}$ hybridization buffer $(52 \mathrm{~g} \mathrm{NaCl}, 20$ $\mathrm{ml}$ Tris-HCL, pH 7.2, $10 \mathrm{ml}$ 10\% SDS in 1 liter demineralized water, filtered through $0.2 \mu \mathrm{m}$ filter) was applied to the slides. EUB338 is a universal bacterial probe, binding more than $98 \%$ of bacteria present in the murine gut. Both the universal probe EUB338 and SFB-specific probes were applied together with a control nonsense probe (NonBact338) that does not bind bacteria to check for specificity $(52,53)$. Next, slides were incubated at $50^{\circ} \mathrm{C}$ overnight in a dark moist chamber in an incubator (Marius). The next day, slides were washed in washing buffer (hybridization buffer without SDS) for 30 minutes at $50^{\circ} \mathrm{C}$, and, after briefly rinsing in ultrapure water, slides were air dried rapidly. Slides were DAPI stained, washed in $1 \mathrm{x}$ $\mathrm{PBS}$, and rinsed shortly in ultrapure water. After rapid drying, slides were mounted with VECTASHIELD (Vector Laboratories) and evaluated under the fluorescent microscope (Leica DM5500; Leica Microsystems).

Morphometrics. For morphometric measurements, jejunal tissues were fixed in 3\% glutaraldehyde in PBS for at least 24 hours. Fixed tissues were embedded in glycol methylacrylate (GMA) (Technovit 7100; Hereaus Kulzer) and $1 \mu \mathrm{m}$ sections were cut with a Reichert-Jung Microtome (Leica) and stained with Alcian Blue 8GX (Sigma-Aldrich) and Periodic Acid (SigmaAldrich) and Schiff's Reagent (Merck) (ABPAS). The diameter $(\mu \mathrm{m})$ of Pc secretory granules was measured by using the Leica Image Manager 500 at a magnification of $\times 100$. In 5-20 crypts per mouse (3-5 mice per group), the diameter of the granules of 2 Pcs was determined.

Immunohistochemistry and electron microscopy. Jejuno-ileal tissues were fixed in $4 \%$ paraformaldehyde, and sections of $4 \mu \mathrm{m}$ thickness were deparaffinized and stained with hematoxylin (Vector Laboratories) and eosin (Sigma-Aldrich) for histological analysis. For immunohistochemistry, sections were deparaffinized and endogenous peroxidases were quenched with $3 \% \mathrm{H}_{2} \mathrm{O}_{2}$ in methanol for 20 minutes. Antigen retrieval was obtained after microwave treatment in citrate buffer (10 mM, pH 6.0). Sections were blocked for 1 hour in 1\% Blocking Reagent (Roche) in PBS and incubated overnight at $4{ }^{\circ} \mathrm{C}$ with rabbit anti-lysozyme (Dako Corporation) diluted 1:50 in PBS. For CDX2, sections were incubated with mouse anti-CDX2 
(BioGenex) diluted 1:500 in PBS. Biotin conjugated lectins Helix pomatia and Triticum vulgaris (Sigma-Aldrich) were incubated overnight at 1:100 and 1:1,000 dilutions, respectively, in TBS plus $1 \mathrm{mM} \mathrm{CaCl}_{2}$. Immunoreaction was detected using VECTASTAIN ABC Elite Kit (Vector Laboratories) and 3,3'-diaminobenzidine tetrahydrochloride (Sigma-Aldrich). Nuclei were counterstained with hematoxylin (Vector Laboratories). For electron microscopy, tissues were fixed in 3\% glutaraldehyde in PBS for 1 week, followed by a postfixation in osmiumtetroxide for 2 hours. Subsequently, tissues were embedded in Epon according to standard procedures. Ultrathin sections were cut with a Reichert Ultramicrotome, and sections were stained with uranylacetate and lead nitrate. Finally, sections were examined with a Philips CM100 at $80 \mathrm{kV}$.

Crypt isolation and incubation. Crypts were isolated by using a published protocol (29). In short, about 5,000 isolated crypts were incubated at $28^{\circ} \mathrm{C}$ in triplicate in Iscove's modified Dulbecco medium (IMDM), either with or without $1 \mu \mathrm{g} / \mathrm{ml} \alpha \mathrm{GalCer}$ and with $5 \times 10^{4}$ invariant mouse NKT cells (line DN32). The IMDM incubation medium was supplemented with penicillin/streptomycin (50 U/ml), azide (0.001\%), PMSF (1 mM), $\beta$-mercaptoethanol $(50 \mu \mathrm{M})$, soybean trypsin inhibitor $(50 \mu \mathrm{g} / \mathrm{ml})$, leupeptin $(10 \mu \mathrm{g} / \mathrm{ml})$, $2 \%$ minimal essential amino acids (50x; Sigma-Aldrich), $0.5 \%$ nonessential amino acids ( $10 \mathrm{mM}$; Cambrex), sodium selenite $(1.3 \mathrm{ng} / \mathrm{ml})$, thyroxine (1.3 $\mathrm{ng} / \mathrm{ml})$, transferrin $(5 \mu \mathrm{g} / \mathrm{ml})$, prostaglandin E1 $(25 \mathrm{ng} / \mathrm{ml})$, tissue culture supplement $(2.00 \mathrm{~g} 200 \times$ concentrated D-galactose, $0.63 \mathrm{mg}$ biotin, $1.30 \mathrm{mg}$ putrescin, $0.45 \mathrm{~g}$ ascorbic acid, $180.00 \mathrm{ng}$ myoinositol, and $1.10 \mathrm{~g}$ sodium pyruvate in $50 \mathrm{ml} \mathrm{H}_{2} \mathrm{O}$ ). Crypts and supernatants were collected by centrifugation for 5 minutes at 13,400 $g$ and prepared for Western blotting.

Lysozyme-p Western blotting. Supernatants were precipitated with acetone, and the pellet was dissolved in $15 \mu$ l SDS-PAGE sample buffer. Crypt fractions were dissolved in $10 \mu \mathrm{l}$ SDS-PAGE sample buffer. Samples were loaded on 15\% SDS-PAGE gels and blotted on nitrocellulose (Protran BA83, $0.2 \mu \mathrm{m}$; Schleicher \& Schuell). Hereafter, blots were blocked for 1 hour with blocking buffer containing $50 \mathrm{mM}$ Tris, $\mathrm{pH} 7.8,5 \%(\mathrm{w} / \mathrm{v})$, nonfat dry milk powder (Campina Melkunie), $2 \mathrm{mM} \mathrm{CaCl}_{2}, 0.05 \%$ (v/v) Nonidet P40 (BioChemica), and $0.01 \%$ Antifoam B (Sigma-Aldrich). Blots were incubated overnight at $4{ }^{\circ} \mathrm{C}$, with rabbit anti-lysozyme $(1: 25)$ and mouse anti- $\beta$-actin $(1: 10,000)$ diluted in blocking buffer. After washing with PBS, $0.2 \%$ Tween- 20 bound antibodies were revealed using HRP-conjugated goat anti-rabbit or goat antimouse secondary antibodies $(1: 1,000)$ and SuperSignal West Femto Luminol
Enhancer kit (Pierce). The signal was detected and quantified by the ChemiGenius gel documentation system (Syngene). Lysozyme-p production in the supernatant was corrected for $\beta$-actin in the crypt fraction.

qPCR for lysozyme-p. We isolated RNA from gut tissue (RNeasy Midi Kit, catalog no. 75144; QIAGEN). cDNA was generated by standard procedures (Becton Dickinson). qPCR assays were performed on an ABI Prism 7700 Sequence Detection System platform (Applied Biosystems). For detection of lysozyme-p, sense primer 5'-GATGGCTACCGTGGTGT-3' and antisense primer 5 '-CACCCATGCTCGAATG- 3 ' were used. For detection of the household gene tubulin-2, sense primer 5'-ATCGATGAAGTTCGCACT-3' and anti-sense primer 5'-TGTAGGGCTCAACCACAG-3' were used.

Statistics. All data were analyzed using unpaired, 2-tailed Student's $t$ test and presented as mean \pm SEM. A $P$ value of less than 0.05 was considered significant.

\section{Acknowledgments}

We thank Andre Ouellette and Terrence Barrett for their critical support throughout the project. We thank Mark Exley, Sean Colgan, Jolanda van Dieren, Lies-anne Severijnen, Hiromi Inaba, Erika Iioka, Keiko Furuya, Colin de Haar, and Pieter van Lierop for technical advice and support and Kirin Pharmaceuticals for generously providing the glycolipids used. E.E.S. Nieuwenhuis was supported by the Ter Meulen Fund, Royal Netherlands Academy of Arts and Sciences, and Netherlands Organisation for Scientific Research (NWO). R.S. Blumberg was supported by NIH grants DK44319, DK51362, and DK53056 and the Harvard Digestive Diseases Center (DK034854). This study was also supported by the Grant-in-Aid for Research of Japan Society for the Promotion of Science (19591184).

Received for publication June 16, 2008, and accepted in revised form February 18, 2009.

Address correspondence to: Edward E.S. Nieuwenhuis, Laboratory of Pediatrics and Department of Pediatric Gastroenterology, Sophia Children's Hospital, MC, Room Sp 3464, Dr. Molewaterplein 50, 3015 GE Rotterdam, The Netherlands. Phone: 31-10-7037093; Fax: 31-10-7036811; E-mail: e.nieuwenhuis@erasmusmc.nl.
1. Hooper, L.V., et al. 2001. Molecular analysis of commensal host-microbial relationships in the intestine. Science. 291:881-884.

2. Ryu, J.H., et al. 2008. Innate immune homeostasis by the homeobox gene caudal and commensal-gut mutualism in Drosophila. Science. 319:777-782.

3. Artis, D. 2008. Epithelial-cell recognition of commensal bacteria and maintenance of immune homeostasis in the gut. Nat. Rev. Immunol. 8:411-420.

4. Macpherson, A.J., and Uhr, T. 2004. Induction of protective IgA by intestinal dendritic cells carrying commensal bacteria. Science. 303:1662-1665.

5. Akira, S., Takeda, K., and Kaisho, T. 2001. Tolllike receptors: critical proteins linking innate and acquired immunity. Nat. Immunol. 2:675-680.

6. Ouellette, A.J. 2006. Paneth cell alpha-defensin synthesis and function. Curr. Top. Microbiol. Immunol. 306:1-25.

7. Salzman, N.H., Underwood, M.A., and Bevins, C.L. 2007. Paneth cells, defensins, and the commensal microbiota: a hypothesis on intimate interplay at the intestinal mucosa. Semin. Immunol. 19:70-83.

8. Ouellette, A.J. 2005. Paneth cell alpha-defensins: peptide mediators of innate immunity in the small intestine. Springer Semin. Immunopathol. 27:133-146.

9. Lacasse, J., and Martin, L.H. 1992. Detection of CD1 mRNA in Paneth cells of the mouse intestine by in situ hybridization. J. Histochem. Cytochem. 40:1527-1534.

10. Balk, S.P., et al. 1994. Beta 2-microglobulin-independent MHC class Ib molecule expressed by human intestinal epithelium. Science. 265:259-262.

11. Bleicher, P.A., et al. 1990. Expression of murine CD1 on gastrointestinal epithelium. Science. 250:679-682.

12. van de Wal, Y., et al. 2003. Delineation of a CD1drestricted antigen presentation pathway associated with human and mouse intestinal epithelial cells. Gastroenterology. 124:1420-1431.

13. Perera, L., et al. 2007. Expression of nonclassical class I molecules by intestinal epithelial cells. Inflamm. Bowel Dis. 13:298-307.

14. Lee, P.T., Benlagha, K., Teyton, L., and Bendelac, A. 2002. Distinct functional lineages of human V(alpha)24 natural killer T cells. J. Exp. Med. 195:637-641.

15. Benlagha, K., Kyin, T., Beavis, A., Teyton, L., and Bendelac, A. 2002. A thymic precursor to the NK T cell lineage. Science. 296:553-555.

16. Kronenberg, M. 2005. Toward an understanding of NKT cell biology: progress and paradoxes. Annu. Rev. Immunol. 23:877-900.

17. Brigl, M., and Brenner, M.B. 2004. CD1: antigen presentation and T cell function. Annu. Rev. Immu- nol. 22:817-890.

18. Zhou, D., et al. 2004. Lysosomal glycosphingolipid recognition by NKT cells. Science. 306:1786-1789.

19. Mattner, J., et al. 2005. Exogenous and endogenous glycolipid antigens activate NKT cells during microbial infections. Nature. 434:525-529.

20. Kinjo, Y., et al. 2005. Recognition of bacterial glycosphingolipids by natural killer T cells. Nature. 434:520-525.

21. Colgan, S.P., Hershberg, R.M., Furuta, G.T., and Blumberg, R.S. 1999. Ligation of intestinal epithelial CD1d induces bioactive IL-10: critical role of the cytoplasmic tail in autocrine signaling. Proc. Natl. Acad. Sci. U. S. A. 96:13938-13943.

22. Yue, S.C., Shaulov, A., Wang, R., Balk, S.P., and Exley, M.A. 2005. CD1d ligation on human monocytes directly signals rapid NF-kappaB activation and production of bioactive IL-12. Proc. Natl. Acad. Sci. U. S. A. 102:11811-11816.

23. Nieuwenhuis, E.E., et al. 2002. CD1d-dependent macrophage-mediated clearance of Pseudomonas aeruginosa from lung. Nat. Med. 8:588-593.

24. Nieuwenhuis, E.E., et al. 2000. Oral antibiotics as a novel therapy for arthritis: evidence for a beneficial effect of intestinal Escherichia coli. Arthritis Rheum. 43:2583-2589.

25. Ivanov, I.I., et al. 2008. Specific microbiota direct 
the differentiation of IL-17-producing T-helper cells in the mucosa of the small intestine. Cell Host Microbe. 4:337-349.

26. Ewing, B., Hillier, L., Wendl, M.C., and Green, P. 1998. Base-calling of automated sequencer traces using phred. I. Accuracy assessment. Genome Res. 8:175-185.

27. Schloss, P.D., and Handelsman, J. 2005. Introducing DOTUR, a computer program for defining operational taxonomic units and estimating species richness. Appl. Environ. Microbiol. 71:1501-1506.

28. Lozupone, C., Hamady, M., and Knight, R. 2006. UniFrac--an online tool for comparing microbial community diversity in a phylogenetic context. BMC Bioinformatics. 7:371.

29. Ayabe, T., et al. 2000. Secretion of microbicidal alpha-defensins by intestinal Paneth cells in response to bacteria. Nat. Immunol. 1:113-118.

30. Peeters, T., and Vantrappen, G. 1975. The Paneth cell: a source of intestinal lysozyme. Gut. 16:553-558.

31. Ouellette, A.J., Satchell, D.P., Hsieh, M.M., Hagen, S.J., and Selsted, M.E. 2000. Characterization of luminal paneth cell alpha-defensins in mouse small intestine. Attenuated antimicrobial activities of peptides with truncated amino termini. J. Biol. Chem. 275:33969-33973.

32. Satoh, Y., Yamano, M., Matsuda, M., and Ono, K. 1990. Ultrastructure of Paneth cells in the intestine of various mammals. J. Electron Microsc. Tech. 16:69-80.

33. Leis, O., Madrid, J.F., Ballesta, J., and Hernandez, F. 1997. N-and O-linked oligosaccharides in the secretory granules of rat Paneth cells: an ultrastructural cytochemical study. J. Histochem. Cytochem. 45:285-293.

34. Shimada, O., et al. 1998. Detection of deoxyribonuclease I along the secretory pathway in Paneth cells of human small intestine. J. Histochem. Cytochem. 46:833-840.

35. Dahan, S., et al. 2008. Epithelial: lamina propria lymphocyte interactions promote epithelial cell differentiation. Gastroenterology. 134:192-203.

36. Beck, F., Chawengsaksophak, K., Waring, P., Playford, R.J., and Furness, J.B. 1999. Reprogramming of intestinal differentiation and intercalary regeneration in Cdx2 mutant mice. Proc. Natl. Acad. Sci. U. S. A. 96:7318-7323.

37. Kinjo, Y., et al. 2006. Natural killer T cells recognize diacylglycerol antigens from pathogenic bacteria. Nat. Immunol. 7:978-986.

38. Jahng, A., et al. 2004. Prevention of autoimmunity by targeting a distinct, noninvariant CD1d-reactive T cell population reactive to sulfatide. J. Exp. Med. 199:947-957.

39. Marks, D.J., et al. 2006. Defective acute inflammation in Crohn's disease: a clinical investigation. Lancet. 367:668-678.

40. Hampe, J., et al. 2007. A genome-wide association scan of nonsynonymous SNPs identifies a susceptibility variant for Crohn disease in ATG16L1. Nat. Genet. 39:207-211.

41. Rioux, J.D., et al. 2007. Genome-wide association study identifies new susceptibility loci for Crohn disease and implicates autophagy in disease pathogenesis. Nat. Genet. 39:596-604.

42. Kaser, A., et al. 2008. XBP1 links ER stress to intestinal inflammation and confers genetic risk for human inflammatory bowel disease. Cell. 134:743-756.

43. Cadwell, K., et al. 2008. A key role for autophagy and the autophagy gene Atg1611 in mouse and human intestinal Paneth cells. Nature. 456:259-263.

44. Kobayashi, K.S., et al. 2005. Nod2-dependent regulation of innate and adaptive immunity in the intestinal tract. Science. 307:731-734.

45. Kaser, A., and Blumberg, R.S. 2008. Paneth cells and inflammation dance together in Crohn's disease. Cell Res. 18:1160-1162.

46. Heller, F., Fuss, I.J., Nieuwenhuis, E.E., Blumberg, R.S., and Strober, W. 2002. Oxazolone colitis, a Th2 colitis model resembling ulcerative colitis, is mediated by IL-13-producing NK-T cells. Immunity. 17:629-638.

47. Nieuwenhuis, E.E., et al. 2002. Disruption of Thelper 2-immune responses in Epstein-Barr virusinduced gene 3-deficient mice. Proc. Natl. Acad. Sci. U. S. A. 99:16951-16956.

48. Fuss, I.J., et al. 2004. Nonclassical CD1d-restricted NK T cells that produce IL-13 characterize an atypical Th2 response in ulcerative colitis. J. Clin. Invest. 113:1490-1497.

49. Saubermann, L.J., et al. 2000. Activation of natural killer $\mathrm{T}$ cells by alpha-galactosylceramide in the presence of CD1d provides protection against colitis in mice. Gastroenterology. 119:119-128.

50. Ueno, Y., et al. 2005. Single dose of OCH improves mucosal $\mathrm{T}$ helper type 1 / $\mathrm{T}$ helper type 2 cytokine balance and prevents experimental colitis in the presence of valpha14 natural killer T cells in mice. Inflamm. Bowel Dis. 11:35-41.

51. Garrett, W.S., et al. 2007. Communicable ulcerative colitis induced by T-bet deficiency in the innate immune system. Cell. 131:33-45.

52. Amann, R.I., Ludwig, W., and Schleifer, K.H. 1995. Phylogenetic identification and in situ detection of individual microbial cells without cultivation. Microbiol. Rev. 59:143-169.

53. Salzman, N.H., et al. 2002. Analysis of $16 \mathrm{~S}$ libraries of mouse gastrointestinal microflora reveals a large new group of mouse intestinal bacteria. Microbiology. 148:3651-3660. 